\title{
Avaliação de métodos de determinação de água disponível em solo cultivado com algodão(1)
}

\author{
Carlos Cleide de Souza ${ }^{(2)}$, Francisco Assis de Oliveira ${ }^{(3)}$, Ivandro de França da Silva ${ }^{(3)}$ \\ e Malaquias da Silva Amorim Neto(4)
}

\begin{abstract}
Resumo - O objetivo deste trabalho foi avaliar dois métodos de determinação de água disponível no solo (um direto e outro de laboratório), e o efeito de três níveis de água disponível (10\%, 25\% e 40\%) na cultura do algodoeiro herbáceo (Gossypium hirsutum L. r. latifolium Hutch). O trabalho foi realizado em casa de vegetação do Departamento de Solos e Engenharia Rural/Centro de Ciências Agrárias/Universidade Federal da Paraíba, Município de Areia, PB. O delineamento experimental adotado foi o de blocos ao acaso, com distribuição em esquema fatorial 2 x 3, com três repetições. Conforme a análise de variância, a faixa de água disponível no solo, encontrada mediante a utilização do método direto, supera significativamente $(\mathrm{p} \leq 0,05)$ a obtida pelo método de laboratório. O manejo das irrigações do algodoeiro com base em $40 \%$ da água disponível, determinado pelo método direto, proporcionou os maiores resultados de evapotranspiração, de área foliar e acumulação de fitomassa na parte aérea da cultura. Observou-se ainda interação métodos x níveis de água disponível em todas as variáveis estudadas.
\end{abstract}

Termos para indexação: Gossypium hirsutum, evapotranspiração, balanço hídrico do solo, manejo de cultura, rendimento.

\section{Evaluation of methods of determination of soil available water in cotton cultivation}

\begin{abstract}
The main objective of this work was to evaluate two methods of determination of soil available water (a direct method and other in laboratory) and the effect of three levels of available water $(10,25$ and $40 \%)$ in cotton crop (Gossypium hirsutum L. r. latifolium Hutch). This work was developed in green house condition in the Departamento de Solos e Engenharia Rural/Centro de Ciências Agrárias/Universidade Federal da Paraíba, located in Areia, PB, Brazil. A completely randomized block was utilized in a $2 \times 3$ factorial arrangement, with three replications. The variance analysis showed that the values of the available water in soil using the direct method were significantly $(\mathrm{p} \leq 0.05)$ bigger than the lab method. The management of irrigation in the cotton crop using $40 \%$ of available water determinated through the direct method showed the better results of evapotranspiration, leaf area, aboveground biomass. There was interaction of methods $\mathrm{x}$ levels of available water for all variables studied.
\end{abstract}

Index terms: Gossypium hirsutum, evapotranspiration, soil water balance, crop management, yields.

\section{Introdução}

A maioria dos trabalhos realizados com o objetivo de estudar o manejo de água no solo considera

(1) Aceito para publicação em 5 de julho de 2001.

Extraído da Dissertação de Mestrado apresentada pelo primeiro autor à Universidade Federal da Paraíba (UFPB), Centro de Ciências Agrárias (CCA), Areia, PB.

(2) UFPB, CCA, Dep. de Solos e Engenharia Rural (DSER), Campus III, CEP 58397-000 Areia, PB. Bolsista do DCRCNPq. E-mail: oliveira@cca.ufpb.br

(3) UFPB, CCA, DSER. Bolsista do CNPq.

E-mail: ivandro@cca.ufpb.br

(4) Embrapa-Centro Nacional de Pesquisa de Algodão, Caixa Postal 174, CEP 58102-000 Campina Grande, PB.

E-mail: amorim@cnpa.embrapa.br como disponível às plantas a água retida entre as tensões equivalentes à capacidade de campo e ao ponto de murcha permanente, determinados em laboratório, conforme Richards (1947). Desta forma, consideram como indicativo do ponto de murcha permanente o teor de água retida no solo sob a tensão de $-1,500 \mathrm{MPa}$, e, como da capacidade de campo, o retido a - 0,033 MPa em solos argilosos e - 0,010 MPa em solos arenosos, independentemente do vegetal cultivado.

Quando, porém, se objetiva o estudo do comportamento da água no solo, com vistas ao manejo adequado das irrigações, deve-se levar em consideração o método utilizado na determinação da capacidade de campo, assim como do ponto de murcha 
permanente. No caso da capacidade de campo, diferenças têm sido observadas entre os diversos métodos, quando comparados com o método direto no campo, considerado o mais preciso, conforme Reichardt (1988), que chama a atenção inclusive para a impressão errônea de que a capacidade de campo é uma característica intrínseca do solo e independente do método empregado em sua determinação. Para esse autor, o método da panela de pressão, descrito por Richards (1947), apesar de fornecer dados práticos aceitáveis, carece de respaldo teórico. A respeito dos métodos empregados na sua estimativa, de acordo com Marshall (1959), citado por Souza \& Reichardt (1996), não existe método de medida em laboratório que possa ser, no campo, um real substituto da capacidade de campo, em virtude de fatores como as características do perfil e as condições iniciais de umidade do solo.

Da mesma forma, acredita-se, acontece com os métodos aplicados na determinação do ponto de murcha permanente, uma vez que a capacidade de retenção de água dos solos varia de acordo com a classe textural, principalmente. Por outro lado, salienta-se que determinadas plantas podem absorver água sob tensões baixas no solo.

Segundo Souza \& Reichardt (1996), o ponto de murcha permanente é normalmente considerado como sendo uma característica estática, ao contrário da capacidade de campo, que, segundo trabalhos recentes, é considerada dinâmica.

A pesquisa tem evidenciado que o algodoeiro é uma planta tolerante a baixos teores de água no solo, diferentemente de culturas como o girassol e o feijão, comumente usadas como plantas teste na determinação do ponto de murcha permanente, pelo método fisiológico direto, conforme Kiehl (1979).

Diferenças entre os valores de ponto de murcha permanente, obtidos a partir da utilização do girassol e os do feijão-caupi como plantas indicadoras, são registradas por Oliveira \& Martins (1966). Os autores ainda verificaram que, em diversos solos da região Nordeste, a utilização do feijão-caupi, como planta indicadora, induz a obtenção de valores de umidade inferiores aos encontrados a -1,500 MPa de potencial matricial, e concluíram que o valor do conteúdo de água a -1,500 MPa está dentro da faixa de água disponível às plantas, podendo, inclusive, na maioria dos casos, substituir o valor encontrado pelo método fisiológico.
Ao trabalharem com solos de diferentes texturas, Cirino \& Guerra (1994) encontraram diferenças significativas entre os valores de ponto de murcha permanente ( $\%$ base solo seco), obtidos pelo método fisiológico, utilizando o feijão-caupi como planta indicadora, e pela curva característica de retenção de água no solo (-1,515 MPa), em que os menores valores de conteúdo de água foram obtidos pelo método fisiológico.

Levando-se em consideração as prováveis variações nos conteúdos de água no solo, quando este se encontra em capacidade de campo e em ponto de murcha permanente, segundo o método de determinação, a faixa de água disponível, ou facilmente disponível, no solo, poderá ser alterada, inclusive com reflexos nos cálculos de lâminas de água para controle das irrigações.

Este trabalho foi conduzido com o objetivo de avaliar dois métodos de determinação e três níveis de água disponível no solo, na cultura do algodoeiro herbáceo.

\section{Material e Métodos}

O experimento foi conduzido em casa de vegetação, pertencente ao Departamento de Solos e Engenharia Rural, do Centro de Ciências Agrárias, da Universidade Federal da Paraíba, localizado no Município de Areia, PB, no período de $15 / 5$ a 20/9/98. O local do ensaio encontra-se a $2 \mathrm{~km}$ ao Norte das coordenadas $6^{\circ} 58^{\prime}$ de latitude Sul, $35^{\circ} 41^{\prime}$ de longitude a Oeste de Greenwich e $575 \mathrm{~m}$ de altitude. De acordo com a classificação de Köppen, o clima da região é do tipo As', que se caracteriza por ser quente e úmido, com chuvas de outono-inverno e período de estiagem de cinco a seis meses.

Utilizou-se como substrato o material de um Regossolo, classificado texturalmente como areia franca, coletado nos $20 \mathrm{~cm}$ superficiais do perfil, cuja análise física revelou 7,8, $18,1,22,7,26,8,10,1,11,3$ e $3,2 \mathrm{dag} \mathrm{kg}^{-1}$ de areia muito grossa, areia grossa, areia média, areia fina, areia muito fina, silte e argila, respectivamente; densidade do solo de $1,40 \mathrm{~kg} \mathrm{dm}^{-3}$ e de partículas de $2,61 \mathrm{~kg} \mathrm{dm}^{-3}$; porosidade total de $46 \%$, sendo $33 \%$ de macro e $13 \%$ de microporos. Pela análise química verificou-se: 3,70, 2,58, 0,21 e 1,12 $\mathrm{cmol}_{\mathrm{c}} \mathrm{dm}^{-3}$ de $\mathrm{Ca}^{2+}, \mathrm{Mg}^{2+}, \mathrm{Na}^{+} \mathrm{e} \mathrm{K}^{+}$, respectivamente; $\mathrm{pH} 7,6 ; 13,44 \mathrm{~g} \mathrm{dm}^{-3}$ de matéria orgânica; e $129 \mathrm{mg} \mathrm{dm}^{-3}$ de P disponível.

Os tratamentos foram definidos por dois métodos de determinação de água disponível no solo, em laboratório e 
em casa de vegetação e três níveis de água disponível no solo, 10,25 e $40 \%$, como indicativo do manejo das irrigações, ou seja, quando o fator de esgotamento chegava a 90 , 75 e $60 \%$ da água disponível, e o solo era irrigado manualmente até atingir a capacidade de campo. O delineamento experimental adotado foi o de blocos ao acaso, distribuídos em esquema fatorial 2 x 3 , com três repetições. A unidade experimental foi representada por um vaso de plástico com capacidade para $20 \mathrm{~L}$, contendo solo secado ao ar, equivalente a $15 \mathrm{~kg}$ de solo secado em estufa.

Considerou-se como método de laboratório (ML) o descrito por Richards (1947), em que a capacidade de campo (CC) corresponde à água retida no solo a um potencial de $-0,010 \mathrm{MPa}$, e o ponto de murcha permanente (PMP), a água retida a um potencial matricial de $-1,500 \mathrm{MPa}$.

Como método direto (MD), foi considerado o procedimento em que a $\mathrm{CC}$ foi determinada por um método gravimétrico direto, e o PMP, com base no método fisiológico, ambos em casa de vegetação. Como CC, considerou-se o conteúdo de água retida pelo solo após sofrer saturação e conseqüente ação da gravidade, cuja determinação foi desenvolvida a partir de quatro vasos contendo o equivalente a $3 \mathrm{~kg}$ de solo secado em estufa. Nos vasos, o solo com estrutura deformada foi umedecido até à saturação por capilaridade, por um período de 12 horas. Como se verificou excesso de água no fundo dos vasos, por estarem em contato direto com a água de embebição, estes foram submetidos à drenagem livre, por um período não inferior a 20 horas, até o total cessamento, sempre com a superfície do solo coberta para evitar a evaporação, oportunidade em que se determinou o conteúdo de água retido. Como PMP, considerou-se o conteúdo de água no solo em que a cultura não conseguia mais absorver água.

Para a determinação do PMP, levou-se em consideração o método descrito por Kiehl (1979), porém sem a necessidade de utilizar o selamento superficial dos solos, nem tampouco a câmara úmida, e utilizando o próprio algodoeiro herbáceo (cultivar CNPA-7H) como plantateste, como segue: a partir de 21 vasos contendo o equivalente a $3 \mathrm{~kg}$ de solo secado em estufa, e adequadamente úmido, dez sementes do algodoeiro foram semeadas; após a emergência das plântulas, duas em cada vaso foram irrigadas regularmente; a partir dos 20 dias após a emergência, foi estabelecido o estresse hídrico com a supressão das irrigações, até que as plantas atingissem o PMP.

O monitoramento da umidade do solo foi viabilizado por meio de amostragens, isto é, à medida que as plantas apresentavam sintomas severos de murcha, coletava-se uma amostra do solo, para determinar o teor de umidade, e em seguida o solo dos vasos era umedecido para ver se as plantas voltariam, ou não, à turgescência, num período nunca inferior a 24 horas. Quando atingiam a turgescência, novas tentativas eram feitas em novos vasos e plantas, a cada 2 a 3 dias, até que todas as plantas senesceram, indicando, assim, o real PMP.

Para testar os tratamentos, foi utilizado o algodoeiro herbáceo (Gossypium hirsutum L. r. latifolium Hutch), cultivar CNPA-7H. Durante a condução do experimento, foram tomados dados de consumo de água, de expansão da área foliar e de acumulação de fitomassa na parte aérea da cultura.

\section{Resultados e Discussão}

Observou-se variação expressiva na faixa de água disponível no solo (AD), em decorrência do método empregado em sua determinação (Tabela 1). Souza et al. (1999) asseguram, inclusive, que tal variação é verdadeira, independentemente da textura do solo em apreço, observando-se sempre a superioridade da faixa de $\mathrm{AD}$ determinada pelo método direto aqui considerado, em razão tanto do aumento do conteúdo de água do solo em capacidade de campo (CC), como da diminuição do conteúdo de água no solo em ponto de murcha permanente (PMP).

A partir dos resultados apresentados na Tabela 1, entende-se que o método de determinação de $\mathrm{AD}$ influenciará diretamente nos cálculos das lâminas de irrigação. Em termos porcentuais, cada um dos níveis, $10 \%, 25 \%$ e $40 \%$ de $\mathrm{AD}$, apresentará valores volumétricos diferentes, influenciando, assim, de maneira diversa, o crescimento/desenvolvimento do algodoeiro.

Pelos resultados da análise de variância constatou-se efeito significativo $(p \leq 0,05)$ dos tratamentos na evapotranspiração da cultura (ETc), expansão de área foliar (AF) e acumulação de

Tabela 1. Conteúdo de água no solo em capacidade de campo (CC) e em ponto de murcha permanente (PMP), determinado pelo método de laboratório e pelo método direto.

\begin{tabular}{lrr}
\hline Método & \multicolumn{2}{c}{ Água no solo $\left(\mathrm{g} \mathrm{kg}^{-1}\right)$} \\
\cline { 2 - 3 } & \multicolumn{1}{c}{$\mathrm{CC}$} & $\mathrm{PMP}$ \\
\hline Laboratório & 95,38 & 35,51 \\
Direto & 181,25 & 11,09 \\
\hline
\end{tabular}


fitomassa na parte aérea (AFA), revelando, inclusive, interação significativa entre métodos $\mathrm{x}$ níveis de AD sobre estas variáveis.

Quanto aos métodos de determinação de AD estudados, o método direto de casa de vegetação superou significativamente o de laboratório, podendo-se quantificar esta superioridade em $40 \%$, $60 \%$ e $39 \%$ para ETc, AF e AFA, respectivamente (Tabela 2 ).

Observou-se redução significativa nos valores das variáveis em apreço, em razão da redução do conteúdo de $\mathrm{AD}$ utilizado como indicativo para o manejo das irrigações (Tabela 2 ).

Tabela 2. Médias relativas ao efeito isolado dos métodos de determinação e níveis de água disponível (AD) na evapotranspiração (ETc), área foliar (AF) e acumulação de fitomassa na parte aérea (AFA) do algodoeiro herbáceo, cultivar CNPA-7H(1).

\begin{tabular}{lccc}
\hline Tratamento & $\mathrm{ETc}(\mathrm{mm})$ & $\mathrm{AF}\left(\mathrm{cm}^{2}\right)$ & $\mathrm{AFA}(\mathrm{g})$ \\
\hline Método & & & \\
$\quad$ Laboratório & $227 \mathrm{~b}$ & $1509 \mathrm{~b}$ & $20,3 \mathrm{~b}$ \\
$\quad$ Direto & $318 \mathrm{a}$ & $2423 \mathrm{a}$ & $28,3 \mathrm{a}$ \\
\hline Níveis de AD (\%) & & & \\
40 & $359 \mathrm{a}$ & $2832 \mathrm{a}$ & $33,3 \mathrm{a}$ \\
25 & $280 \mathrm{~b}$ & $1898 \mathrm{~b}$ & $22,9 \mathrm{~b}$ \\
10 & $178 \mathrm{c}$ & $1167 \mathrm{c}$ & $16,7 \mathrm{c}$ \\
\hline Média & 272 & 1966 & 24,3 \\
CV (\%) & 12 & 28 & 24,4 \\
DMS/método & 35 & 583 & 6,2 \\
DMS/níveis de AD & 53 & 880 & 9,4 \\
\hline (1) Médias seguidas de mesma letra não diferem entre si pelo teste de Tukey \\
a 5\% de probabilidade; DMS: diferença mínima significativa pelo teste de \\
Tukey a 5\% de probabilidade.
\end{tabular}

Ao se estudar o efeito dos níveis de água disponível dentro de cada método observou-se que a diferença entre os valores das variáveis foi mais expressiva no MD, com destaque para o nível de $40 \%$ (Tabela 3 ). Este resultado demonstra coerência com as observações de Souza et al. (1999), que, sem levar em consideração o método empregado na determinação da $\mathrm{AD}$, verificaram que a utilização de nível igual ou superior a $25 \%$ da $\mathrm{AD}$ causa efeito altamente depressivo sobre estas variáveis. Levando em consideração, porém, os dados obtidos neste trabalho para o ML, observa-se que não houve diferença entre os níveis de $\mathrm{AD}$ testados em relação a $\mathrm{AF}$ e AFA. Apenas na ETc o nível de $10 \%$ foi superado pelos demais, que não diferiram entre si.

Ao se estudar o efeito dos métodos dentro de cada nível de $\mathrm{AD}$, a superioridade do MD só foi verificada no nível de $40 \%$ (Tabela 3 ). Observou-se que, apesar de o MD exibir maior conteúdo de água no solo em condições de CC, este método também condicionou a obtenção de conteúdo de água muito baixo em condições de PMP (Figura 1), o que tornase prejudicial para a cultura quando se trabalha com nível igual ou inferior a 25\%. Esses níveis também são considerados inviáveis quando determinados pelo ML, por afetar o estado hídrico da planta. Para Moreshet et al. (1996), o estado hídrico das plantas depende do balanço entre o influxo do solo e o efluxo para a atmosfera. Segundo os autores, quando o conteúdo de água do solo é sensivelmente reduzido, há uma diminuição do contato com as raízes, onde a extração é mais intensa, interrompendo o fluxo, podendo ser reversível com a irrigação.

Tabela 3. Médias relativas ao efeito da interação método de determinação X níveis de água disponível (40\%, 25\% e $10 \%$ ) a evapotranspiração (ETc), área foliar (AF) e acumulação de fitomassa na parte aérea (AFA) do algodoeiro herbáceo, cultivar CNPA-7H(1).

\begin{tabular}{|c|c|c|c|c|c|c|c|c|c|}
\hline \multirow[t]{2}{*}{ Método } & \multicolumn{3}{|c|}{ ETc } & \multicolumn{3}{|c|}{$\mathrm{AF}$} & \multicolumn{3}{|c|}{ AFA } \\
\hline & $40 \%$ & $25 \%$ & $10 \%$ & $40 \%$ & $25 \%$ & $10 \%$ & $40 \%$ & $25 \%$ & $10 \%$ \\
\hline & \multicolumn{3}{|c|}{------------ (mm) ------------ } & \multicolumn{3}{|c|}{$\left(\mathrm{cm}^{2}\right)$------ } & \multicolumn{3}{|c|}{------------ (g) --------- } \\
\hline Laboratório & $263 \mathrm{bA}$ & $261 \mathrm{aA}$ & $156 \mathrm{aB}$ & $1.744 \mathrm{bA}$ & $1.720 \mathrm{aA}$ & $1.061 \mathrm{aA}$ & $23,4 \mathrm{bA}$ & $21,8 \mathrm{aA}$ & $16,0 \mathrm{aA}$ \\
\hline Direto & $455 \mathrm{aA}$ & $298 \mathrm{aB}$ & $201 \mathrm{aC}$ & $3.919 \mathrm{aA}$ & $2.077 \mathrm{aB}$ & $1.273 \mathrm{aB}$ & $43,1 \mathrm{aA}$ & $24,0 \mathrm{aB}$ & $18,0 \mathrm{aB}$ \\
\hline CV (\%) & & 12,2 & & & 28,3 & & & 24,4 & \\
\hline DMS/coluna & & 60,3 & & & $1.010,0$ & & & 10,8 & \\
\hline DMS/linha & & 74,3 & & & $1.244,0$ & & & 13,3 & \\
\hline
\end{tabular}

(1) Médias seguidas de mesma letra, minúsculas nas colunas e maiúsculas nas linhas, não diferem entre si pelo teste de Tukey a 5\% de probabilidade; DMS diferença mínima significativa pelo teste de Tukey a 5\% de probabilidade. 
Em termos de interação métodos x níveis de $\mathrm{AD}$, os maiores resultados foram observados no método direto, principalmente quando se trabalhou com o nível de $40 \%$ de $\mathrm{AD}$ em relação a todas as variáveis (Tabela 3), sugerindo, que o melhor nível de AD utilizado como indicativo para reposição da água consumida pela cultura, depende diretamente do método empregado na sua determinação, como sugerem Andrade et al. (1992).

\section{Conclusões}

1. A faixa de água disponível no solo, determinada pelo método direto em condições de vaso, supera a obtida pelo método de laboratório.

2. O nível de água disponível no solo mais indicado para manejo das irrigações, na cultura do algodoeiro, depende diretamente do método empregado na sua determinação.

3. O manejo das irrigações do algodoeiro com base em $40 \%$ da água disponível, determinado pelo método direto, é suficiente para proporcionar o maior desenvolvimento da área foliar, acumulação de fitomassa na parte aérea e conseqüente aumento na taxa de evapotranspiração da cultura.

\section{Referências}

ANDRADE, C. L. T. de; FREITAS, J. A. D. de; LUZ, L. R. Q. P. da. Características de solos arenosos de tabuleiros litorâneos. In: CONGRESSO NACIONAL DE IRRIGAÇÃO E DRENAGEM, 9., 1991, Natal. Anais... Fortaleza: Associação Brasileira de Irrigação e Drenagem, 1992. p. 1069-1095.
CIRINO, C. G.; GUERRA, H. O. C. Utilização das relações energia/umidade na caracterização físico-hídrica dos solos. Pesquisa Agropecuária Brasileira, Brasília, v. 29, n. 12, p. 1973-1978, dez. 1994.

KIEHL, E. S. Manual de edafologia: relações solo-planta. São Paulo: Ceres, 1979. 262 p.

MORESHET, S.; FUCHS, M.; COHEN, Y.; COHEN, Y.; LANGENSIEPEN, M. Water transport characteristics of cotton as affected by drip irrigation layout. Agronomy Journal, Madison, v. 88, n. 5, p. 717-722, 1996.

OLIVEIRA, L. B. de; MARTINS, A. M. C. M. Considerações sobre a umidade de 15 atmosferas e a umidade de murcha (método fisiológico), em solos do Nordeste. Pesquisa Agropecuária Brasileira, Rio de Janeiro, v. 1, p. 91-95, 1966.

REICHARDT, K. Capacidade de campo. Revista Brasileira de Ciência do Solo, Campinas, v. 12, n. 13, p. 211-216, 1988.

RICHARDS, L. A. Pressure-membrane apparatus, construction and use. Agronomy Engineering, Madison, n. 28, p. 451-454, 1947.

SOUZA, C. C. de; OLIVEIRA, F. A. de; SILVA, I. de F. da; ANDRADE, A. P. de. Manejo da irrigação e da adubação nitrogenada na cultura do algodoeiro herbáceo.

Revista Brasileira de Engenharia Agrícola e Ambiental, Campina Grande, v. 3, n. 2, p. 125-130, 1999.

SOUZA, L. D.; REICHARDT, K. Estimativas da capacidade de campo. Revista Brasileira de Ciência do Solo, Campinas, v. 20, n. 2, p. 183-189, 1996. 